\title{
Prevalence and pathological lesion of Trichomonas gallinae in pigeons of Iran
}

\author{
H. Borji • G. H. Razmi • A. H. Movassaghi • \\ E. Moghaddas $\cdot$ M. Azad
}

Received: 5 April 2011/Accepted: 25 May 2011/Published online: 4 June 2011

(C) Indian Society for Parasitology 2011

\begin{abstract}
This research was conducted to determine the prevalence and pathological lesion of Trichomonas gallinae in pigeons in the northeast part of Iran. Wet mount preparations from the oral cavity/crop of 418 pigeons (Columba livia) captured from various locations in Khorasan province analyzed for T. gallinae by Giemsa's staining between April 2008 and June 2009. A total of 418 pigeons, 37.32\% $(n=156)$ were infected with $T$. gallinae. Macroscopically, the oropharynx of infected pigeons has white, caseous lesions or stomatitis. Microscopically, there was moderate congestion with infiltration of mononuclear inflammatory cells in the lamina propria of pharynx, hyperplasia of mucous cells in epithelia of trachea with infiltration of mononuclear inflammatory cells, numerous granulomatous foci in the livers with many multinucleated giant cells, tubulointerstitial nephritis with multifocal to diffuse infiltration of mostly mononuclear inflammatory cells in the kidneys. In the present paper we have described for the first time the co-existence of both genotypes of $T$. gallinae based on pathological lesions in this area.
\end{abstract}

Keywords Trichomonas gallinea P Prevalence ·

Pathology $\cdot$ Iran

\section{Introduction}

Trichomonas gallinae is an economically important pathogen, since it affects avian livestock and poses a

H. Borji ( $)$ · G. H. Razmi · A. H. Movassaghi ·

E. Moghaddas · M. Azad

Department of Pathobiology, School of Veterinary Medicine,

Ferdowsi University of Mashhad, P.O. Box 9177948974,

Mashhad, Iran

e-mail: hborji@um.ac.ir considerable threat to the conservation of threatened species of columbid, and their avian predators. Despite the parasite's preference for pigeons and doves, $T$. gallinae can affect a wide range of bird families, and infections in bustards (Silvanose et al. 1998), psittacine birds (Baker 1996; McKeon et al. 1997), fowl (McDougald and Calnek 2000) and passerine birds (Cousquer 2005) have been reported. Parasites live mainly in the bird's anterior digestive tract, where they can cause granulomatous lesions that occlude the oesophagic lumen, leading to the death of birds as a result of severe starvation. However, it is well known that virulence of the strains varies and some can reach parenquimatous organs and generate necrotic foci (Prez-Mesa and Stabler 1960; Narcisi et al. 1991).

Studies with $T$. gallinae have demonstrated a wide spectrum of virulence. With highly virulent isolates, a bird can succumb to infection within 14 days after being inoculated with a single trichomonad, whereas with avirulent isolates, a bird may fail to even seroconvert after being inoculated with $1 \times 106$ organisms (Stabler and Kihara 1954). Additionally, it has been demonstrated that clinically normal pigeons can harbor both avirulent and virulent isolates. However, naive doves and pigeons challenged with a mixture of virulent and avirulent isolates will succumb to infection (Stabler 1954).

Pigeons are distributed all over of Iran and few information is available in the literature on pathological effects and virulence of Trichomonas gallinae (Pirali-Kheirabadi et al. 2008). It is not known whether T. gallinae is a single species or a group of species and whether virulent strains are present in eastern part of Iran. Therefore, this research was conducted to determine the prevalence of $T$. gallinae and pathological effect of infection on pigeons in Khorasan province of Iran. 


\section{Materials and methods}

The area studied was a region on the northeast of Iran, Khorasan province, which is characterized by a low humid climate, with cold winters and hot summers. For a period of 1 year (April 2008 to June 2009) a total of 418 domestic pigeons (Columba livia) were sampled. In the case of pigeons, 310 samples were taken from wild birds while 108 were obtained from pigeon lofts. Wild birds were captured in the course of a pest control program undertaken by the local authorities using cage traps in public parks located in urban areas. Pigeons from lofts were captured in situ and were released after sampling. The wet mount prepared from the oral cavity/crop of pigeons was smeared in slide and staining with Giemsa for T. gallinae.

The oropharynx of pigeons was examined macroscopically for the presence of white, caseous lesions or stomatitis as an indicator for trichomonosis. After sampling, the birds were humanely euthanized and different parts of pigeons including oropharynx, kidney, liver and lung were collected for pathological changes. Tissue specimens were preserved in $10 \%$ formalin solution and processed by routine histopathological techniques and stained with haematoxylin and eosin and examined histologically.

\section{Results}

Thin wet smear examination showed that $37.32 \%$ of pigeons (156/418) was infected with $T$. gallinae.

In moderately infested birds, there were hyperemia, scattered hepatocellular necrosis, bile duct hyperplasia and infiltration of heterophils and mononuclear inflammatory cells in the livers. Lungs were severely congested with infiltration of mononuclear inflammatory cells. There was moderate congestion with mild renal tubular necrosis and multiple foci of mononuclear inflammatory cells in the kidneys. Mild to moderate infiltration of mononuclear inflammatory cells was noted in the lamina propria of the larynx and pharynx. There were large foci of heterophils and mononuclear inflammatory cells in the tracheal mucosa (Fig. 1-1).

In highly infested birds, there was moderate congestion with infiltration of mononuclear inflammatory cells in the lamina propria of the larynx and pharynx. There was also hyperplasia of mucous cells in epithelia of trachea with infiltration of mononuclear inflammatory cells. Lungs showed severe congestion. Numerous granulomatous foci were noted in the livers with many multinucleated giant cells (Fig. 1-2). There was tubulointerstitial nephritis with multifocal to diffuse infiltration of mostly mononuclear inflammatory cells in the kidneys (Fig. 1-3).
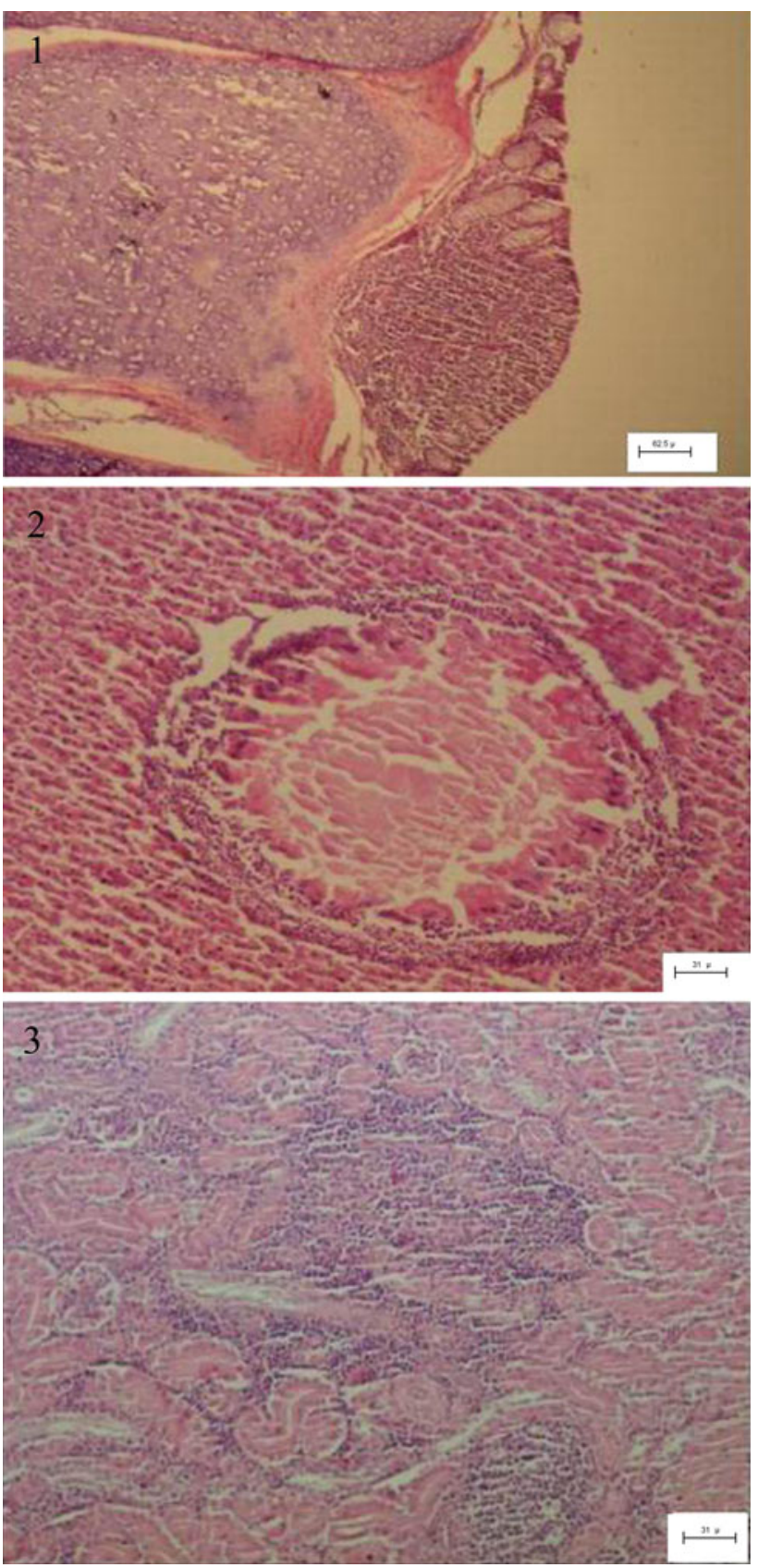

Fig. 11 Heavy infiltration of heterophils and mononuclear inflammatory cells in the tracheal mucosa. Hematoxylin and eosin $(160 \times) .2$ Granulomatous lesion with multiple giant cells in the liver of affected bird. Hematoxylin and eosin $(320 \times) .3$ Tubulointerstitial nephritis in the kidney of affected pigeon. Hematoxylin and eosin $(320 \times)$

\section{Discussion}

Columbidae are known as the parasite's main host, particularly the domestic pigeon $(C$. livia), which has been considered responsible for the worldwide spread of T. gallinae (Harmon et al. 1987).

The prevalence of $T$. gallinae found in pigeons $(37.32 \%)$ was similar to the values found by Villanua et al. (2006) 
and Sansano-Maestre et al. (2009) in Spain and lower than reported from other regions of Iran (Derakhshanfar et al. 2004; Pirali-Kheirabadi et al. 2008). Data on prevalence found in Columbidae by different authors throughout the world vary greatly, ranging from $5.6 \%$ cited by Schulz et al. (2005) in mourning doves (Zenaida macroura) to 95\% detected by Conti and Forrester (1981) in whitewinged doves (Zenaida asiatica) in the USA. In Spain, Hfle et al. (2004) reported an outbreak of trichomonosis in the south that affected $15 \%$ of wintering woodpigeons (Columba palumbus). Variations in season, age or bird species could explain these differences in prevalence between the studies. Differences in prevalence between captive and wild birds have been demonstrated, proving to be higher in the first. In Australia, McKeon et al. (1997) observed a prevalence of $49 \%$ in captive pigeons, compared with $46 \%$ in wild birds. More remarkable differences were described in Saudi Arabia by Bailey et al. (2000), who detected a prevalence of $35 \%$ in wild pigeons and $68 \%$ in captive birds.

Only $0.5 \%$ of infected pigeons displayed lesions at the time of sampling. Similar results were observed by Bunbury et al. (2008) and Sansano-Maestre et al. (2009), who detected a small number of birds with clinical symptoms in pigeon from Mauritius and Spain. This could be explained by the fact that it is usually difficult to find very sick birds because they tend to hide or attract predators. In addition, the carcasses of birds that have died from disease are rapidly eradicated by other carrion feeders, which would make them impossible to detect (Peterson et al. 2000).

It is note that low to high rate of pathologic changes is the result of $T$. gallinae heterogeneity and low and high virulence of strain caused trichomonosis in eastern of Iran. Although, Pirali-kheirabadi et al. (2008) found that low virulence strains caused trichomonosis in Center of Iran. Strain variation as an explanation of differential virulence for avian trichomonads is well established (BonDurant and Honigberg 1994) and may contribute to the fluctuating levels of infection, morbidity and mortality observed within pigeon subpopulations. Virulence also depends on other factors such as previous exposure to the pathogen (protective immunity) and individual immunocompetence. The latter can be affected by factors such as age, concurrent disease, genetic heterogeneity and food availability (Stabler and Braun 1975; Swinnerton et al. 2005). In the present paper we have described for the first time the co-existence of both genotypes of $T$. gallinae based on pathological lesions in this area. The existence of these genotypes supports the need for genetic characterization of the isolates in order to establish more consistent differences between isolates, including host adaptation and virulence of different strains.
Acknowledgments This work was supported by the Ferdowsi University of Mashhad (grant number 154). We thank Mr. H. Eshrati and Mr. Azari for his technical assistance during data collection and Mr. Mohammadnejad for taking pictures.

\section{References}

Bailey TC, Samour JH, Bailey TA, Remple TD, Remple CJ, Redig PT, Cooper JE, Hunter DB (eds) (2000) Trichomonas sp. and falcon health in the United Arab Emirates. Raptor biomedicine III. University of Minnesota Press, Minneapolis, pp 53-57

Baker JR (1996) Causes of mortality and morbidity in exhibition budgerigars in the United Kingdom. Vet Record 139:156-162

BonDurant RH, Honigberg BM (1994) Trichomonads of veterinary importance. Parasitic Protozoa Academic Press, New York, pp 111-206

Bunbury N, Jones CG, Greenwood AG, Bell DJ (2008) Epidemiology and conservation implications of Trichomonas gallinae infection in the endangered Mauritian pink pigeon. Biol Conserv 141: 153-161

Conti JA, Forrester DJ (1981) Interrelationships of parasites of whitewinged doves and mourning doves in Florida. J Wildlife Dis 17:529-536

Cousquer G (2005) Ingluvitis and oesophagitis in wild finches. Vet Record 157:445

Derakhshanfar A, Radfar MH, Taefinasrabadi N (2004) A study on parasites of the digestive system and related lesions of pigeons in City of Kerman, Iran: Pathological Findings. In: 29th world congress of the world small animal veterinary association, Rhodes, Greece

Harmon WH, Clark WA, Hawbecke AC, Stafford M (1987) Trichomonas gallinae in columbiform birds from Galapagos Islands. J Wildlife Dis 23:492-494

Hfle U, Gortzar C, Ortiz JA (2004) Outbreak of trichomoniasis in a woodpigeon (Columba palumbus) wintering roost. E J Wildlife Res 50:73-77

McDougald LR, Calnek BW (2000) Protozoaria Diseases of Poultry. Iowa University State Press, Ames, pp 924-926

McKeon T, Dunsmore J, Raidal SR (1997) Trichomonas gallinae in budgerigars and columbid birds in Perth, Western Australia. Aust Vet J 175:65-652

Narcisi EM, Sevolan M, Honigberg BM (1991) Pathologic changes in pigeons infected with a virulent Trichomonas gallinae strain (Eigberg). Avian Dis 35:55-61

Peterson CA, Lee SL, Elliot JE (2000) Scavenging of waterfowl carcasses by birds in agricultural fields of British Columbia. Can Field Naturalist 72:150-159

Pirali-Kheirabadi K, Shakhse-Niaie M, Hosseini N (2008) Epidemiological aspects of pigeon trichomonosis in center of Iran. Res J Parasitol 3:20-24

Prez-Mesa C, Stabler R (1960) Histopathological changes in the domestic pigeon infected with Trichomonas gallinae (Jone's barn strain). Avian Dis 5:48-60

Sansano-Maestre J, Garijo-Toledo MM, Gómez-Muñoz MT (2009) Prevalence and genotyping of Trichomonas gallinae in pigeons and birds of prey. Avian Pathol 38:7-201

Schulz JH, Bermdez AJ, Millspaught JJ (2005) Monitoring the presence and annual variation of trichomoniasis in mourning doves. Avian Dis 49:387-389

Silvanose CD, Samour JH, Naldo JL, Bailey TA (1998) Oropharyngeal protozoa in captive bustards: clinical and pathological considerations. Avian Pathol 27:226-230

Stabler RM (1954) Trichomonas gallinae: A review. Exp Parasitol 3:368-402 
Stabler RM, Braun CE (1975) Effect of virulent Trichomonas gallinae on the band-tailed pigeon. J Wildlife Dis 11:482-483

Stabler RM, Kihara JT (1954) Infection and death of the pigeon resulting from the oral implantation of single individuals of Trichomonas gallinae. J Parasitol 40:706

Swinnerton KJ, Greenwood AG, Chapman RE, Jones CG (2005)

The incidence of the parasitic disease trichomoniasis and its treatment in reintroduced and wild pink pigeons Columba mayeri. Ibis 147:772-782

Villanua D, Hfle U, Prez-Rodrguez L, Gortzar C (2006) Trichomonas gallinae in wintering common wood Pigeons Columba palumbus in Spain. Ibis 148:641-648 